\title{
Histochemical Evidence of a Cholestatic Period in Neonatal Rats
}

\author{
C. De Wolf-Peeters ${ }^{[33]}, \mathrm{R}$. De Vos, and V. Desmet \\ Laboratorium voor Histochemie en Cytochemie, Academisch Ziekenhuis St. Rafaël, Leuven, Belgium
}

\begin{abstract}
Extract
Histochemical staining of alkaline phosphatase was performed on liver tissue of three groups of Wistar rats: (group I) 44 fetuses between 14 days gestational age and birth; (group 2) 76 neonatal rats between 0 and 10 days of age and; (group 3) 44 neonatal rats between $0 \mathrm{hr}$ and 10 days of age, born to dams subjected to bile duct ligation 2 days before delivery.

In tissue from animals of group 1 a progressive evolution was observed in the pattern of "canalicular" staining and in the degree of positive reaction obtained.

In tissue from animals of group 2 a striking deviation from the usual staining pattern observed at birth was seen from the 12th hr on, returning gradually to "normal" by the 10 th day. This change resembled different cholestatic conditions seen in tissue of adult rats. From the 6th hr until the 2nd day a slight accumulation of histochemically detectable conjugated bilirubin was observed.

In animals from group 3 a similarly "abnormal" alkaline phosphatase picture was observed at birth $(0 \mathrm{hr})$, whereas no bilirubin could be visualized. The findings seen in animals of group 2 suggest the occurrence of a cholestatic phenomenon in early neonatal life of normal rats, presumably caused by temporary immaturity of the liver secretory function, hepatocytes or bile ducts, or both. The results found in animals of group 3 indicate that the sequence of changes observed in the neonatal period can be accelerated by enforcing a secretory load upon the fetal liver.
\end{abstract}

\section{Speculation}

A secretory immaturity of the liver cell seen in neonatal rat liver tissue could also exist in human neonatal liver, and may be an important factor in different conditions of human neonatal jaundice. One could further speculate whether the so-called "inspissated bile syndrome" observed in young children with severe hemolysis might not be partly due to a similar immaturity of the excretory mechanisms of the liver cell.

\section{Introduction}

A deficiency of the bilirubin-conjugating system exists in the normal newborn mouse, rabbit, guinea pig, rat, and in man $[7,22]$. It has been shown that the accumulation of unconjugated bilirubin acts as a trigger for the conjugating system $[2,5]$. A similar mechanism was proposed to explain the finding of conjugated bilirubin immediately after birth in the cord blood of children severely affected by erythroblastosis fetalis [4].

During a histochemical study of postmortem fetal liver specimens from fetuses ranging from 28.5 to 33 
weeks of agc, microscopically visible bile accumulation was found in cases of erythroblastosis. This bile pigment showed histochemical staining characteristics of conjugated bilirubin. The presence of conjugated bile pigment in the form of intracellular granules and extracellular thrombi was interpreted as indirect evidence of immaturity of the final excretory capacity of fetal and neonatal liver [10]. From these findings it seemed interesting to study the histochemical differentiation of the biliary pole of the hepatocyte during fetal and postnatal life, inasmuch as functional as well as morphologic information about liver cell membranes may be obtained by cytochemical staining reactions for phosphatases [23, 27].

\section{Materials and Methods}

Rats of albino Wistar $\mathrm{R}$ strain were obtained commercially [28]. During the experiment all rats were fed a laboratory diet and tap water ad libitum. Female rats were placed with males overnight and examined the next morning for the presence of sperm in the vaginal smear. The day of observation of sperm was counted as day 1 of pregnancy [6]. Fetuses and newborn animals used in this study can be divided into three groups.

Group 1 comprised 44 rat fetuses between the 14 th and the 22nd day of gestation. They were obtained by successive cesarean sections performed in mother rats under constant flow ether anesthesia; group 2 was composed of 76 normal neonatal rats between birth and 10 days of age or older; and group 3 comprised 44 newborn rats of increasing age from birth to 10 days of age. These animals were borne by dams which had undergone ligation of the common bile duct 2 days before expected delivery. The bile duct was doubly Iigated and sectioned between the ligatures. The livers of the fetuses and neonatal rats were quickly removed after decapitation of the animals. Two samples of the right half of the median liver lobe were taken. One sample was immediately quenched in liquid nitrogencooled isopentane. Cryostat sections, $9 \mu$ thick, were cut [29], fixed for $15 \mathrm{~min}$ in cold formol-calcium chloride-dextran [24], and stained for alkaline phosphatase, using the calcium-cobalt method of Gomori [14]. Incubation time was $30 \mathrm{~min}$ at $37^{\circ}$. Serial sections were stained with Fouchet's reagent [15] for demonstrating total bilirubin, and with the diazonium salt of ethylanthranilate [8] for visualizing conjugated bile pigment. The second specimen was fixed in Bouin's fixative and embedded in paraffin; sections stained with hematoxylin and cosin served as a morphological control.

\section{Results}

During the fetal period (studied from the 14th day), peculiar plump structures with a positive alkaline phosphatase reaction were found. These canaliculuslike structures became longer and more numerous with. a maximal development at the 18th and 19th day of gestation. From the 20th day and later, these larger structures disappeared, so that just before birth the whole liver lobule was negative except for some very thin regular canaliculi. The condition remained the same during the first 12 hr after birth (Fig. 1). Between 12 and $24 \mathrm{hr}$ after birth the staining reaction for alkaline phosphatase became intensely positive (at $12 \mathrm{hr}$ the reaction was still negative, at $24 \mathrm{hr}$ the whole liver lobule was always positive) (Fig. 2). Canalicular structures were found over the whole liver lobule, but the morphology was quite different from that found in adult rat liver. Indeed, these structures displayed no general portal-centrilobular orientation; they were large and irregular in form, showing several plump and short side branches and very large saccular dilatations at the points of mutual junction; enzyme reaction was intensely positive. During the following 10 days these canaliculi became thinner and more regular in form; short and narrow side branches appeared which became progressively longer. In the same period (10 days) the reaction for alkaline phosphatase weakened over the whole liver lobule and disappeared progressively in the centrilobular and midzonal area (Fig. 3). After 10 days a histochemical picture was obtained identical to that of normal adult rat liver, showing a weak positive reaction in fine and regular canaliculi limited to a narrow periportal zone (Fig. 4).

The results obtained in newborn rats from dams with obstructed bile ducts differed markedly from those found in normal newborn rats. These animals showed a positive reaction for alkaline phosphatase at birth (Fig. 5). Canalicular structures were stained over the whole liver lobule: they were thin, regular in form, and showed some arrangement along a portal-centrilobular axis as in adult rat liver. At 2 days of age these structures showed an additional increase in intensity of the histochemical reaction. They also assumed a more irregular morphology, becoming slightly dilatated and showing saccular formations (Fig. 6). During the following 10 days the reaction for alkaline phosphatase in these livers weakened progressively while the positivity in the centrilobular area disappeared. The saccular formations were replaced by numerous short side branches; thin and regular canaliculi reappeared in increasing numbers (Figs. 7 and 8). 

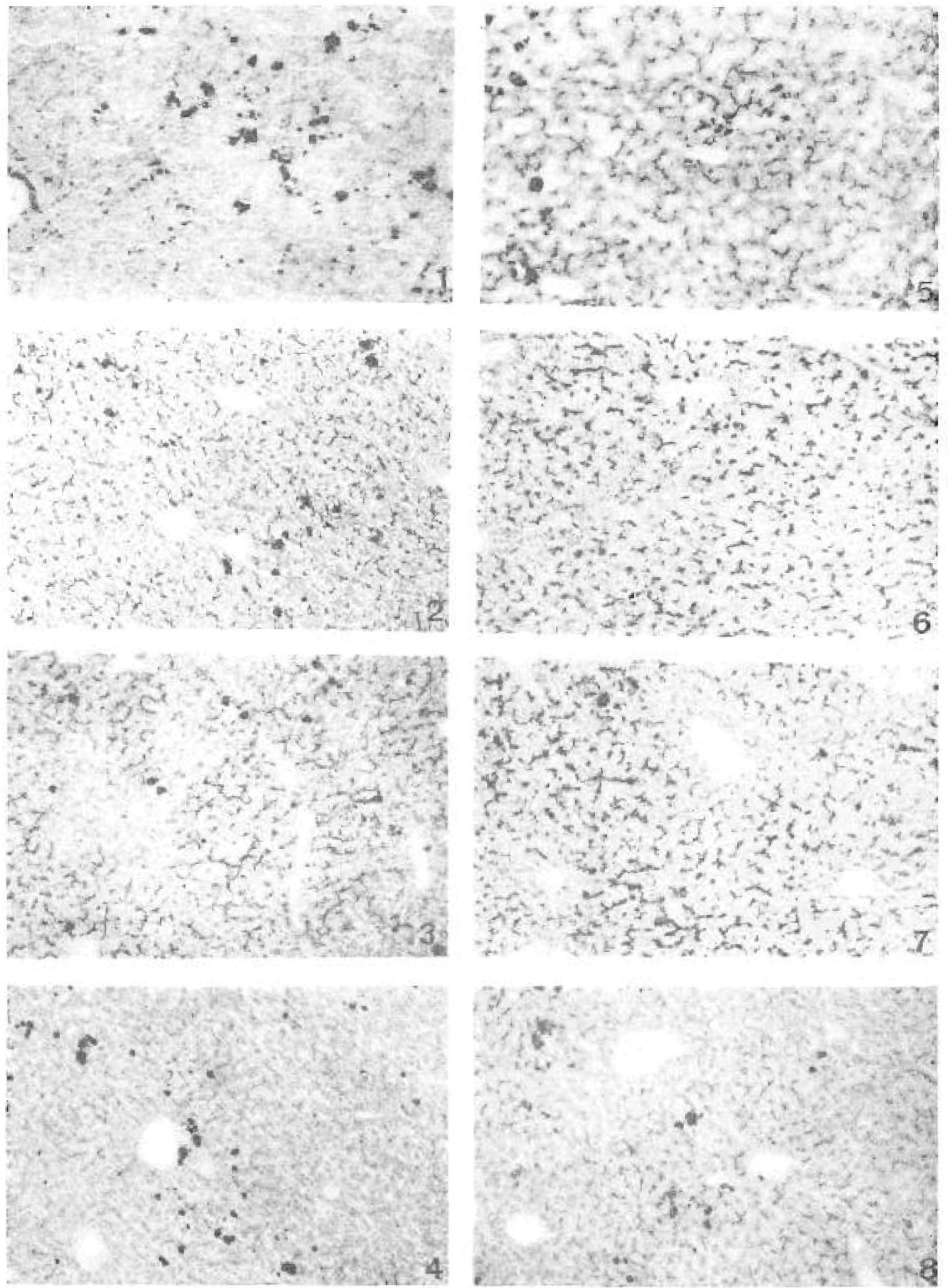

Rat liver tissue: fresh-frozen sections incubated for $30 \mathrm{~min}$ in Gomori's medium for alkaline phosphatase. Figs. 1-4. Normal neonatal rats: $0 \mathrm{hr}, 24 \mathrm{hr}, 3$ days, and 7 days after birth. Figs. 5-8. Nconatal rats born from a mother rat with ligation of the bile duct 2 days before delivery: $0 \mathrm{hr}, 24 \mathrm{hr}, 3$ days, and 7 days after birth. For explanation see text. The larger black foci correspond with hematopoietic tissue. 
In sections stained for bilirubin, using either Fouchet's reagent or the ethylanthranilate technique, we found no bile pigment in liver tissue of fetuses or newborn rats from dams with bile duct obstruction. In the liver of normal neonatal rats, however, a slight degree of microscopic cholestasis was found during the first $48 \mathrm{hr}$ of life. This pigment accumulation occurred in the form of intracellular granules, intracanalicular thrombi, and small bilirubin plugs in the periportal area. This bile pigment stained positively with both the diazonium salt of ethylanthranilate and Fouchet's reagent.

\section{Discussion}

The precise nature of the peculiar plump structures exhibiting positive alkaline phosphatase reaction with maximal development at the 18 th-19th day of gestation is not elucidated at the present time. Electron-microscopic studies are under way to solve this problem. The results obtained during fetal life (group l), however, prove that at birth normal rat liver tissue does not show canalicular staining with the histochemical techniques for alkaline phosphatase used in these experiments. From $12 \mathrm{hr}$ on, a striking increase in alkaline phosphatase was found, showing positively stained canaliculi over the entire liver lobule. Comparable changes are known to occur in several pathologic conditions of adult liver when hepatocytes are put under stress. This is the case in ligation of the bile duct, intoxication with icterogenin, with 17-ethyl, 19-nortestostcrone, or with $\alpha$-naphthyl isothiocyanate $[9,13,18]$. In these experimental conditions the increase in alkaline phosphatase activity at the canalicular side is accompanied by an abnormal canalicular morphology and a simultaneous positive staining at the sinusoidal and intercellular membranes. It is important to note that in our experiments this increase in alkaline phosplatase coincided with the presence of small amounts of microscopically visible conjugated bile pigment in liver cells and canaliculi. These combined findings suggest that the increased alkaline phosphatase activity in this period reflec:s a functional stress of the hepatocytes which is due to a deficient secretory capacity, evidence for the latter being the occurrence of stagnating bile components. It must be noted, however, that the cholestatic features seen in neonatal rat livers differed from the cholestatic picture found in adult liver. Staining for alkaline phosphatase was found neither in sinusoids nor at intercellular membranes in neonatal rat liver, whereas in adult rat liver bile pigment could never be detected by optical microscopy [25]. 'Thus, it seems that the normal newborn rat passes through an early period in life characterized by an immaturity of the excretory function of the liver cell. This temporary insufficiency of the excretory capacity of the liver might be analogous with the immaturity of the bilirubin conjugating system, which is known to exist in the fetus and in the newborn and which can be triggered by an increase in unconjugated bilirubin $[1,2,5]$. A point of difference between these reports $[1,5]$ and our findings, however, needs to be elucidated. In the biochemical experiments of Bakken no glucuronyltransferase activity could be detected in normal neonatal rat liver during the first 2 clays of life, whereas in our experiments an accumulation of conjugated bilirubin was found during this period. Several factors can be considered to explain this apparent contradiction. First, the validity of the technique for demonstrating conjugated bilirubin, as used in this study, has been questioned [21]. The suspicions raised against the ethylanthranilate method, however, cannot be sustained inasmuch as the criticism was based on results obtained on paraffin sections stained with an incubation mixture quite different from the one originally described and used in this study [8]. Furthermore, we have repeated all control experiments for the ethylanthranilate technique, achieving the same results as those reported previously. Therefore, we still assume that bile pigments reacting positively with the ethylanthranilate procedure correspond with bilirubin conjugates. Second, the difference in approach between the study of Bakken $[1,5]$ and our experimental design may explain the conflicting evidence reported for an active conjugating system at birth. There is evidence that the method [20] used by Bakken is Iess sensitive than the biochemical method [26] from which the histochemical technique we used is derived. Finally, the possibility exists that the conjugated bilirubin that we detected is not bilirubinglucuronide but another bilirubin conjugate. This last hypothesis would fit in with the findings of Bakken and would correlate with the results olstained by Ferery et al. [11] and Kuenzle [19]. Indeed, these authors have demonstrated the existence of bilirubin conjugates other than bilirubinglucuronide in nomal and abnomal human and rat bile. It has also been shown that the diazonium salt of ethylanthranilate reacts not only with bilirubinglucuronicle but also with the newly discovered bilirubin conjugates [16, 17]. Our findings are consistent with the results obtained by Gartner and Arias [12] in biochemical experiments on newborn guinea pigs, which 
show that in these neonatal animals the excretory capacity of the liver cell is the rate-limiting step for bilirubin metabolism and secretion.

Young rats from dams with ligated bile ducts showed a histochemical picture which, with regard to staining intensity, was comparable to that seen in normal rats $12-24 \mathrm{hr}$ after birth. This finding, together with the absence of demonstrable bile pigment, suggests that these animals were in a further stage of functional development of the liver. It appears that the secretory load, forced upon the liver during the last 2 days of gestation, has hastened the maturation of the excretory capacity of the liver cells. These results agree with the hypothesis recently put forward by Bakken [3]. From clinical observations this author suggests that an increase in unconjugated bilirubin could be the trigger for the bilirubin conjugating system, and that an increase in conjugated bile pigment in turn may be one of the triggering mechanisms for inducing the excretory function of the liver cells.

In rats born to dams with obstructed bile ducts we noted an increase in alkaline phosphatase reaction together with very abnormal canalicular morphology from the 2nd day on. This condition gradually disappeared after a few days but at a slightly slower rate than that observed in normal neonates. Preliminary results lead us to assume that bile components retained in the maternal blood may appear in the milk. This would explain the observation that livers of these neonates, suckling from mothers with ligated bile ducts, show slower evolution to the normal adult pattern because they suffer from an additional cholestatic phenomenon caused by an overload of maternal bile components ingested together with the milk.

It may be concluded that the findings in normal newborn rats point toward the existence of an immaturity of the capacity of the liver. Just as the conjugating system of the hepatocyte can be triggered by an overload of unconjugated bilirubin, so it appears from our results, in animals born to dams with obstructed bile ducts, that an enforced secretory overload of the secretory function of the liver may accelerate the maturation of this mechanism. This secretory immaturity of the liver cell at birth could also be important in different conditions of human neonatal jaundice.

\section{Summary}

The enzymatic-histochemical differentiation of the hepatocyte was investigated during fetal and neonatal life in rats. The findings in normal neonatal rats point toward the existence of a cholestatic phenomenon in early neonatal life presumably caused by temporary immaturity of the secretory function of the liver. The sequence of changes observed in the neonatal period can be accelerated by enforcing a secretory load upon the fetal liver, results apparently obtained in animals born to dams with obstructed bile ducts.

\section{Addendum}

Recently, bilirubin uridine diphosphate-glucuronyl transferase activity was assayed with the incubation procedure of Van Roy and Heirwegh [26] in newborn rats (Thaler, M.: Substrate-induced conjugation of bilirubin in genetically deficient newborn rats. Science, 170: $555(1970))$.

\section{References and Notes}

1. BAKkev, A. F.: Effects of unconjugated bilirubin on bilirubin-UDP-glucuronyl transferase activity in liver of newbom rats. Pediat. Res., 3: 205 (1969).

2. BAKKFN, A. F.: Bilirubin excretion in newborn human infants. I. Unconjugatted bilirubin as a possible trigger for bilirubin conjugation. Acta Pacdiat. Scand., 59: 148 (1970).

3. BAKKEN, A. F.: Bilirubin excretion in newborn human infants. II. Conjugated bilirubin as a possible trigger for bilirubin excretion. Acta Paediat. Scand., 59: 153 (1970).

4. BAKKEN, A. F., AND Fog, J.: Bilirubin conjugation in the newborn. Lancet, $i i$ : 1280 (1967).

5. BАKKEN, A. F., AND FOG, J.: Bilirubin conjugation in newborn rats. Lancet, iii: 309 (1967).

6. Channers, M.: The copulation plug technic for detection of mating of the "Norway rat". In: W. Lane-Petter et al.: The UFAW Handbook on the Care and Management of Laboratory Animals, ed. 3, p. 386 (Livingstone, London, 1967).

7. Dawkins, M. J. R.: Biochemical aspects of developing function in newborn mammalian liver. Brit. Med. Bull., 22: 27 (1966).

8. Desmet, V. J., Bullens, A. M., De Groote, J., and Herrwech, K. P. M.: A new diazo reagent for specific staining of conjugated bilirubin in tissue sections. J. Histochem. Cytochem., 16: 419 (1968).

9. Desmet, V. J., Krstulovic, B., And Van Damme, B.: Histochemical study of rat liver in alpha-naphthyl isothiocyanate (ANIT) induced cholestasis. Amer. J. Path., 52: 401 (1968).

10. De. Wolf-Peeters, C., Molns-Bullens, A. M., Van Assche, A., AND DESMET, V. J.: Conjugated bilirubin in foetal liver in erythroblastosis. Lancet, $i$ : 471 (1969).

11. Fevery, J., Van Damme, B., Heirwegh, K., and Degroote, J.: Altered composition of bilirubin conjugates in the bile after obstruction. In: Abstracts of 5th Meeting EASL, Bern, September 3-5, 1970.

12. Gartner, L. M., and Arias, I. M.: The transfer from blood to bile in the neonatal guinea pig. Pediat. Res., 3: 171 (1969).

13. Goldfischer, S., Arias, I. M., Essner, E., and Novikoff, A. B.: Cytochemical and electron microscopic studies of rat liver 
with reduced capacity to transport conjugated bilirubin. J. Exp. Med., 115: 467 (1962).

14. Gomori, G.: Microscopic Histochemistry; Pxinciples and Practice. (University of Chicago Press, Chicago, 1952).

15. Hat.., M. J. A.: A staining reaction for bilirubin in sections of tissues. Amer. J. Clin. Path., 3f: 313 (1960).

16. Heirwegh, K. P. M., Van Hees, G. P., Compernom.t., F., and Frvery, J.: Excretion in dog bile of bilirubin conjugated with glucose. Biochem. J., 120: 17p (1970).

17. Heirwegin, K., Van Hees, G. P., Lreroy, P., Van Roy, F. P., AND JANSEN, F. H.: Heterogeneity of bile pigment conjugates as revealed by chromatography of their ethylanthranilate atopigments. Biochem. J., 120:877 (1970).

18. Kretulovic, B., Van Damme, B., and Desmet, V. J.: Comparative histochemical study of rat liver in bile duct ligation and in alpha-naphthyl isothiocyanate (ANIT) intoxication. Amcr. J. Path., 52: 423 (1968).

19. Kurvar., C. C.: Bilirubin conjugates of human bile. Biochem. J., 119: $411(1970)$.

20. LAThe, G. H., AND Walker, M.: The synthesis of bilirubin glucuronide in animal and human liver. Biochem. J., 70: 705 (1958).

21. Lliflit, R. 1), and Pizzolato, P.: Histochemical azo coupling reactions of the pigments of obstructive icterus and of hematoidin. I. Diazonium salts used. J. Histochem. Cytochem., I7: 738 (1969).

22. Neubaur, J., and Hollmany, S.: Dic Aktivität der Glucuronyltransferase in der Leber des menschlichen feten und Frühgeborenen. Klin. Wochenschr., 44: 723 (1966).
23. Novikorf, A. 13., AND Essirr, E.: The liver cell, some new approaches to its study. Amer. J. Med., 29: 102 (1960).

24. Pianteydt, H. T.: Maag en Maagcarcinoom. Een Histochemisch Onderzock. (Proefschrift, n.v., Batteljec \& Terpstra, Leiden, 1961).

25. Popprer, H.: Cholestasis. Annu. Rev. Med., 19: 39 (1968).

26. VAN Roy, F. P., AND HFirwegh, K. P. M.: Determination of bilirubin glucuronide and assay of glucuronyltransferase with bilirubin as acceptor. Biochem. J., 107:507 (1968).

27. Wir.s, E. J., AND EPstein, H. A.: Subcellular changes in surface adenosine triphosphatase activity of human liver in extrahepatic obstructive jaundice. Amer. J. Path., 49: 605 (1966).

28. Proefdierencentrum, Heverlec, Belgium.

29. Cryostat system Dittes I)uspiva, Heidelberg, Germany.

30. The authors are most grateful to Miss Ria Cillard, Mrs. SeysTanghe, and Miss Amme Van Houtte for invaluable technical help. They are also indebted to Mr. Michel Rooselecers for the photographic work and to Mrs. Smets-Honsia for preparation of the manuscript.

31. Part of this work was presented at the Fifth Mecting of the European Association for the Study of the Liver in Bern, September 1970.

32. Supported by a grant from the Nationaal Fonds voor Weten. schappelijk Geneeskundig Onderzock of Belgium.

33. Requests for reprints should be addressed to: C. DF. Wor.FPreTrer, M.D., I aboratorium voor Histochemic en Cytochemic, Academisch Ziekenhuis St. Rafaël, Minderbroederstraat 12, 3000 Leuven, Belgium.

34. Accepted for publication February 25, 1971 